\title{
¿ANTICOMUNISMO SIN COMUNISMO? \\ LA CONSTRUCCIÓN DEL FEMINISMO \\ COMO ENEMIGO ESTRATÉGICO DE \\ LAS NUEVAS DERECHAS Y EL DILEMA \\ DE LA REPRODUCCIÓN SOCIAL ${ }^{12}$
}

Julia Esperanza Exposito ${ }^{3}$

Matias Leandro Saidel ${ }^{4}$

\author{
ANTI-COMMUNISM WITHOUT COMMUNISM? THE CONSTRUCTION \\ OF FEMINISM AS A STRATEGIC ENEMY OF NEW RIGHT \\ MOVEMENTS AND THE DILEMMA OF SOCIAL REPRODUCTION \\ ANTICOMUNiSMO SEM COMUNISMO? A CONSTRUÇÃO DO \\ FEMINISMO COMO INIMIGO ESTRATÉGICO DAS NOVAS \\ DIREITAS E O DILEMA DA REPRODUÇÃO SOCIAL
}

Fecha de recepción: 14 de enero del 2021

Fecha de aceptación: 15 de marzo del 2021

Disponible en línea: 30 de abril del 2021

\begin{abstract}
Sugerencia de citación. Exposito, J.E. y Saidel, M. L. (2021). ¿¿Anticomunismo sin comunismo? La construcción del feminismo como enemigo estratégico de las nuevas derechas y el dilema de la reproducción social. Razón Crítica, (11), 255-288. https://doi.org/10.21789/25007807.1746
\end{abstract}

\footnotetext{
(1) Agradecemos a lxs revisorxs anónimxs por sus valiosas sugerencias.

(2) El artículo forma parte de nuestra investigación en Conicet y del Proyecto de Investigación y Desarrollo 5.132 "Política y subjetividad en el capitalismo neoliberal: gubernamentalidad, desposesión y construcción de lo común" (FTS-UNER).

(3) Licenciada en Ciencia Política, Universidad Nacional de Rosario, magíster en Estudios Culturales, CEI, Universidad Nacional de Rosario y doctora en Ciencias Sociales de la Universidad de Buenos Aires. Investigadora posdoctoral de Conicet. Jefe de trabajos prácticos de "Análisis político" (4. año, Ciencia Política), Facultad de Ciencias Política, Universidad Nacional de Rosario. Argentina | expositojulia@gmail.com | https://orcid.org/0000-0001-5671-1934

(4) Doctor en Filosofía Política del Istituto Italiano di Scienze Umane. | Investigador adjunto del Conicet-Ines. Profesor titular de Filosofía Política en la Facultad de Trabajo Social de la Universidad Nacional de Entre Ríos, Argentina msaidel@fts.uner.edu.ar | https://orcid.org/0000-0002-6188-1257
} 


\section{R E S U M E N}

Este trabajo reflexiona sobre la construcción del feminismo y la 'ideología de género' como enemigos estratégicos de las nuevas derechas y la potencialidad de los feminismos de abolir el estado de cosas existentes. En ese marco, se analizan discursos que buscan mostrar el peligro que representaría la 'ideología de género' para la civilización capitalista, occidental y cristiana; se los sitúa en la disputa en torno a la reproducción biosocial, en la cual las luchas feministas cuestionan las jerarquías entre los géneros, la sexualidad, la familia y los modos del trabajo que las derechas defienden. A su vez, la cuestión del género será indagada en su relación compleja con ciertos marxismos y con la potencia política de los feminismos anticapitalistas. Estos últimos, además de realizar demandas al Estado en términos de derechos, objetan la expropiación y explotación del trabajo reproductivo, que es fundamental para la acumulación del capital. En ese contexto, se pregunta si estos feminismos no solo pueden hacer tambalear al patriarcado y a la familia tradicional, sino también habilitar la producción de formas de vida que no obedezcan a las jerarquías económicas, sexo-genéricas y raciales que las nuevas derechas buscan defender a toda costa.

PALA BRAS CLAVE: Feminismos; reproducción biosocial; (anti)comunismo; nuevas derechas; marxismo. 


\section{A B S T R A C T}

This work reflects on the construction of feminism and the so-called "gender ideology" as strategic enemies of New Right movements and the potential of feminisms in trying to abolish the status quo. Within this framework, we will examine the discourses created around this issue to show the danger that the "gender ideology" would represent for Western, capitalist, and Christian civilization, placing such discourses in the dispute over biosocial reproduction, in which feminist struggles question the hierarchies among genders, sexuality, family, and the ways of working promoted by right-wing movements. Additionally, the gender issue will be explored in its complex relationship with certain Marxist insights and the political power of anti-capitalist feminist groups. These groups, besides making demands to the State in terms of rights, stand against the expropriation and exploitation of reproductive labor, which is crucial for the accumulation of capital. In this context, we wonder if such feminisms could not only shake patriarchal structures and the traditional concept of family, but also enable the creation of ways of living that do not obey the economic, sex-generic and racial hierarchies that the New Rights will try to protect at any price.

Keywords: Feminisms; biosocial reproduction; (anti) communism; New Right movements; Marxism.

\section{R E S U M O}

Neste trabalho, é refletido sobre a construção do feminismo e a "ideologia de gênero" como inimigos estratégicos das novas direitas e a potencialidade dos feminismos de abolir o estado de coisas existentes. Nesse âmbito, são analisados discursos que procuram mostrar o perigo que a ideologia de gênero representaria para a civilização capitalista, ocidental e cristã; são situados na disputa acerca da reprodução biossocial, na qual as lutas feministas questionam as hierarquias entre os gêneros, a sexualidade, a família e os modos do trabalho que as direitas defendem. Por sua vez, a questão do gênero é indagada em sua relação complexa com certos marxismos e com a potência política dos feminismos anticapitalistas. Estes últimos, além de realizarem demandas ao Estado em termos de direitos, visam à expropriação e à exploração do trabalho reprodutivo, que é fundamental para a acumulação do capital. Nesse contexto, pergunta-se se esses feminismos não somente podem debilitar o patriarcado e o conceito de família tradicional, mas também habilitar a produção de formas de vida que não obedecem às hierarquias econômicas, sexogenéricas e raciais que as novas direitas buscam defender a todo custo.

PALAVRAS-CHAVE: feminismos; reprodução biossocial; (anti)comunismo; novas direitas; marxismo. 
Nosotros llamamos comunismo al movimiento real que anula y supera al estado de cosas actual. Las condiciones de este movimiento se desprenden de la premisa actualmente existente.

MARX, K., \& ENGELS, F, LA IDEOLOGÍA ALEMANA.

En la última década, hemos sido testigos de dos fenómenos relacionados: por un lado, el auge de nuevas derechas caracterizadas por una fuerte impronta xenófoba, misógina, racista, patriarcal, clasista y aporofóbica; por otro, el progresivo ascenso del movimiento feminista como eje articulador tanto de la crítica del capitalismo neoliberal-colonialheteropatriarcal y de las formas de violencia que este suscita, como de la producción de subjetividades resistentes y de nuevas formas de vida, de militancia y de apertura.

En ese marco, la batalla cultural de las nuevas derechas da lugar a un anticomunismo sin comunismo, si por tal término entendemos la existencia de una alternativa sociopolítica al capitalismo o un movimiento de masas que busca explícitamente poner en común los medios de producción y reproducción, además de las fuentes de la riqueza colectiva. Este macartismo extemporáneo se verifica hoy en el ámbito internacional y, muchas veces, va de la mano del antifeminismo. Por ejemplo, en Estados Unidos es frecuente descalificar como 'comunista' a toda iniciativa que ponga algún límite a la mercantilización de la vida o a cualquier intervención del Estado en la vida económico-social, como sucede con la salud pública. En Brasil, Bolsonaro propuso prohibir el 'comunismo' y la 'ideología de género's . En Argentina, el gobierno de Alberto Fernández

5 Respecto de lo segundo: "A las pocas horas de su toma de posesión, el presidente brasileño Bolsonaro, conocido por su dilatado historial de comentarios homófobos, despojó al Ministerio de Derechos Humanos de sus competencias en los asuntos lgbtq y nombró a Damares Alves, una 
es tildado por sectores de derecha como comunista, con la agravante de haber promovido la Ley de Interrupción Voluntaria del Embarazo.

En efecto, han proliferado por todo el continente las demostraciones de rechazo a la 'ideología de género', a la interrupción voluntaria del embarazo, a la militancia feminista e incluso al lenguaje inclusivo. Los movimientos y referentes neonazis encuentren así cobijo en las movilizaciones, en las redes sociales e incluso en algunos programas televisivos. Esta tormenta de odio constante contra el comunismo y el feminismo se articula en un eje central de varios movimientos de las nuevas derechas: el combate a la 'ideología de género'.

En trabajos pasados, hemos comentado esta construcción del enemigo imaginario como una estrategia discursiva que habilita una contrarrevolución sin revolución (Saidel, 2019), la cual se refleja en nuevas formas de control de las poblaciones a través del aparato represivo y legal (Harcourt, 2018). Asimismo, hemos abordado en profundidad un análisis de las resistencias teórico-políticas de los feminismos de la reproducción social frente a los lineamientos de las derechas (Expósito, 2020). Sin embargo, más allá de un análisis objetivo de las relaciones de fuerzas actuales, cabría preguntarse: ¿cómo pensar la relación entre anticomunismo y antifeminismo en estas nuevas derechas? ¿Es el feminismo una amenaza similar a la representada otrora por el comunismo para el capitalismo? ¿Es el feminismo el nuevo comunismo en el sentido de abolir y superar el actual estado de cosas? ¿Hay algo inherentemente anticapitalista en los feminismos contemporáneos o se trata solo de una construcción paranoica de sus detractores? ¿Estamos ante una demostración de que el patriarcado es una estructura de dominación y de explotación comprendida en una relación unitaria con el capitalismo? ¿Obedece este odio al feminismo como lo 'meramente cultural' o existe aquí una disputa en torno a los costos y modalidades de la reproducción económica y biosocial?

A partir de estos interrogantes, en lo que sigue nos proponemos caracterizar, por un lado, esta construcción del feminismo y la 'ideología de género' como enemigos estratégicos de las nuevas derechas; por el otro, la potencialidad de los feminismos anticapitalistas de construirse hoy en

pastora ultraconservadora, ministra de la Mujer, Familia y Derechos Humanos, y también de los pueblos indígenas. Alves sostiene que las políticas de diversidad han puesto en peligro a la familia brasileña y que, con la nueva administración, ya "no habrá más adoctrinamiento ideológico de los niños y los adolescentes en Brasil. [...] Las niñas serán princesas y los niños serán príncipes” (Mudde, 2021, s/p) 
el 'comunismo' del siglo xxi, es decir, en su capacidad tanto teórica como política para comprender lo que nos acontece y devenir el movimiento capaz de abolir el estado de cosas existentes.

Para esto, y puesto que el presente trabajo se basa en el análisis situado de un corpus teórico, nos proponemos realizar una elaboración crítico-interpretativa de las producciones escogidas, con el objetivo de establecer sistematizaciones conceptuales que den cuenta tanto de la complejidad de los procesos y conceptos trabajados como de sus alcances para el pensamiento social contemporáneo. Siguiendo a la epistemología feminista, entendemos que la principal tarea de toda investigación consiste en situar a la producción de conocimiento, reponiendo tanto su dimensión política como histórica. Esto implica reconocer la contingencia histórica radical de toda producción teórica, así como de lxs sujetxs productores (Haraway, 1995). Asimismo, esta epistemología situada supone un gesto crítico. Por esto, entendemos que poner a jugar a los feminismos y en particular a los de la reproducción social supone ubicarlos y ubicarnos dentro de lo que Fraser (2008) llama 'las nuevas teorías críticas'. Estas premisas metodológicas posibilitan identificar los principales temas de las teorizaciones feministas escogidas y su relación antagónica con las producciones de la nueva derecha consideradas en este texto, así como situarlas a ambas en el contexto del capitalismo neoliberal.

En ese marco, nos preguntaremos por los motivos por los cuales el feminismo ocupa el lugar del enemigo interno dejado vacante por el subversivo, el terrorista, etc., y el modo en que lo hace, según estas nuevas derechas. Para esto, en primer lugar, analizaremos ciertos discursos que buscan mostrar el peligro de la ideología de género para la civilización capitalista, occidental y cristiana, centrándonos en algunos postulados de El libro negro de la nueva izquierda, escrito por Agustín Laje y Nicolás Márquez (2016). Comentamos este texto, donde el feminismo y la 'ideología de género' son caracterizados como pantallas del neomarxismo, porque este documento sintetiza muchos de los postulados y temores de las nuevas derechas, además de por su gran difusión e influencia entre el público latinoamericano. Si bien las hipótesis del libro carecen de fundamentos históricos y teóricos, nos parece interesante para pensar las potencialidades del feminismo y el rechazo que genera en estos sectores. En ese marco, la cuestión de la reproducción social será tratada como un elemento central en las luchas feministas tanto por el odio que genera entre los defensores del capitalismo heteropatriarcal como por su 
relación compleja con ciertos marxismos y con la potencia política de los feminismos.

Nuestra hipótesis es doble. Por un lado, la necesidad de construir un enemigo responde a la lógica antagónica de toda construcción de identidades políticas. Las nuevas derechas movilizan así el odio y el rechazo hacia todxs aquellxs extrañxs a la norma blanca, heterosexual, patriarcal y capitalista. A su vez, este discurso adquiere nuevos bríos frente a una extendida crisis económica y reproductiva. En ese sentido, los feminismos cuestionan las jerarquías que las nuevas derechas buscan defender o restaurar, especialmente en lo que refiere a la relación entre los géneros, la sexualidad, la familia y los modos del trabajo, y descubren las formas actuales de producir valor mediante cuerpos sexo-generizados y racializados. Incluso, al ser el feminismo un movimiento que no busca afirmar una identidad, sino volverse transversal a distintas luchas sociales, se presenta como un blanco estratégico a destruir.

En segundo lugar, más allá de la perimida oposición reformarevolución y en ausencia de un enemigo visible que aglutine el propio campo de las derechas, los feminismos, al menos en sus versiones más radicales, representan en la actualidad el movimiento de resistencia más potente al capitalismo neoliberal, puesto que, además de demandar derechos al Estado, cuestionan la expropiación y explotación del trabajo reproductivo - gratuito, informal, precarizado, sobreexplotado, asalariado y no asalariado, subsidiado y endeudado, financiarizado-, que es fundamental para la acumulación del capital. En ese contexto, los feminismos hacen tambalear al patriarcado y a la familia tradicional, al tiempo que permiten la producción de formas de vida que no obedecen a las jerarquías económicas, sexo-genéricas y raciales que las nuevas derechas buscan sostener a toda costa.

\section{LAS NUEVAS DERECHAS Y LA NECESIDAD DE CONSTRUIR ENEMIGXS}

La necesidad de identificar un enemigo como un modo de construir el propio grupo es tan vieja como la civilización humana. Esta constitución siempre opera a través de exclusiones y en relación con una alteridad. Carl Schmitt (1984) sostuvo que el mundo humano no era un universo, sino un pluriverso, por lo cual la humanidad no tiene una entidad política. De hecho, la distinción política fundamental es entre amigo y enemigo 
(Schmitt, 1984). Laclau (2004), quizás uno de los últimos pensadores del conflicto político-democrático, afirmó que no hay política sin antagonismo y que la identidad siempre se construye en referencia a un exterior constitutivo. En un sentido similar, Sartre (1948) sostuvo que 'el judío' era construido como tal por sus otros; Beauvoir (2019), que la mujer era construida por sus opresores, y Said (2009), que el orientalismo sirvió no solo para justificar la dominación colonial, sino fundamentalmente para construir la propia identidad occidental.

El fin de la guerra fría supuso una victoria aplastante del capitalismo en su fase neoliberal sobre el bloque socialista. Sin embargo, el fin de la historia celebrado por el hegelianismo liberal no implicó el fin del antagonismo político. Desde entonces, una vez que el enemigo comunista se desdibujó, el Imperio ha construido nuevos enemigos. Por un lado, ha dirigido guerras policiales contra distintas amenazas al libre despliegue de las fuerzas de mercado en sus márgenes geopolíticos. Por otro, al interior de las naciones occidentales se despliegan nuevos focos de conflicto, que han favorecido una radicalización de antagonismos hasta ahora subyacentes que se han agudizado en el terreno económico, nacional, etnocultural y sexo-genérico. Concretamente, el triunfo aplastante de la globalización neoliberal supuso un incremento estrepitoso de las desigualdades económicas, no solo entre regiones, sino al interior de cada espacio geográfico, donde la competencia entre la fuerza de trabajo en el contexto internacional ha favorecido la posición del capital para devaluar, subordinar y precarizar cada vez más al trabajo y a la reproducción social. A esto se suma la inmigración masiva que tuvo lugar luego de la descolonización a las antiguas metrópolis de personas expulsadas de sus lugares de origen por razones económicas, bélicas, culturales o políticas. Por su parte, esta etapa coincidió con el progresivo auge de un movimiento de mujeres, lesbianas, trans, travestis y feministas; esta corriente objeta las jerarquías que aún subsisten entre los géneros, los sexos, las razas, las naciones y las clases en los diversos planos de la existencia.

Mientras duró lo que William Davies (2016) señalaba como etapa normativa o hegemónica del neoliberalismo (1989-2008), este parecía poder mostrar ciertos rasgos progresistas en el terreno político-cultural (Fraser \& Sunkara, 2019). Sin embargo, con el estallido de la crisis financiera del 2008, las contradicciones se agudizaron e ideologías políticas de extrema derecha, que parecían estar condenadas a una escasa influencia en la escena pública, se volvieron cada vez más centrales. Estas derechas extremas mostraron no solo una especie de "retorno de 
lo reprimido", sino también hicieron evidente los rasgos autoritarios del propio neoliberalismo, cuyos defensores más 'progresistas', e incluso algunos detractores, parecían incapaces de reconocer.

En ese contexto, al mismo tiempo que surgieron nuevos movimientos sociales y políticos que cuestionaron al sistema económico y el poder neoliberal, se han fortalecido otros que buscan nuevos chivos expiatorios que deben ser combatidos para restaurar un pasado imaginario donde los verdaderos ciudadanos (blancos, varones, propietarios y cristianos) mandaban sin ser perturbados. De este modo, hay un papel estratégico, para las derechas radicales, del miedo a un otro, habitualmente racializado y generizado, que amenaza 'nuestra' forma de vida y que 'nos' roba nuestro trabajo, 'nuestra' propiedad y 'nuestro' goce.

Estas nuevas derechas contienen un variopinto mosaico de tendencias político-ideológicas. A grandes rasgos, cabe distinguir entre extremas derechas neofascistas, que, salvando excepciones, como Amanecer Dorado o la alt-right ${ }^{6}$, tienen una injerencia marginal en el plano político de las derechas radicales o populismos de derechas, que en la última década han cosechado grandes éxitos políticos y culturales. Este último grupo, a su vez, puede dividirse en una rama social-identitaria (Ramas San Miguel, 2019) o rojiparda (Forti, 2020) y otra neoliberal-autoritaria (Ramas San Miguel, 2019) o nacional-liberal (Sauvetre, 2019). La primera, de menor influencia en Occidente, busca dar forma a una nueva síntesis de una crítica a la globalización neoliberal en defensa del bienestar económico de lxs ciudadanxs - excluyendo a lxs extranjerxs - con la afirmación de valores morales tradicionales - familia, propiedad, patria, etc.- . Es decir, combina una crítica socioeconómica hacia el neoliberalismo con un reaccionarismo cultural y político. La segunda, más influyente, con Trump y Bolsonaro a la cabeza, promueve una mayor liberalización de la economía combinada con un autoritarismo político, económico y cultural, que trata de poner en su lugar a lxs inmigrantxs, lxs pobrxs y las subjetividades feminizadas. ${ }^{7}$ A pesar de sus diferencias, ambas vertientes 
de las nuevas derechas comparten la promoción del odio a lxs extranjerxs, al feminismo y al movimiento LGTBIQ ${ }^{8}$. En ese contexto, el feminismo y, en particular, la ‘ideología de género' se vuelven blancos privilegiados para ser atacados.

\title{
LA 'IDEOLOGÍA DE GÉNERO’ COMO ENEMIGO ESTRATÉGICO
}

\author{
Como señalábamos, en la última década surge con fuerza una nueva \\ derecha, tanto en el ámbito político-social como en el intelectual, que \\ tiene como enemigo estratégico al feminismo y la 'ideología de género'. \\ La derecha configura esta subversión en el plano de las identidades \\ sexo-genéricas y las prácticas sexo-afectivas, y relaciona la defensa de los \\ derechos de las subjetividades feminizadas con una avanzada comunista. Si \\ bien esta enemistad hacia el feminismo crítico está presente en la mayoría \\ de los movimientos políticos de la nueva derecha mundial, el discurso \\ de odio hacia la 'ideología de género', lo que incluye una cruzada contra \\ el aborto y la educación sexual integral, resulta especialmente intenso \\ en América Latina ${ }^{9}$. Como señala Nicolás Dvoskin, la extrema derecha \\ latinoamericana con mayor influencia es la que podríamos definir:
}

El primero de ellos es la moralidad: el proponer que las crisis sociales se basan en una modernidad carente de valores y buenas costumbres,

\footnotetext{
a la retórica historicista, modelos o proyecciones de futuro: la nación en construcción debía construirse civilizando al indígena, transformando al trabajador o construyendo una clase social dirigente. Los neoautoritarismos del siglo xxi, en cambio, miran sobre todo al pasado, a momentos perdidos en los que hubo homogeneidad étnica y paz social, un pasado desaparecido por la irrupción de estos nuevos enemigos: inmigrantes que cambiaron el paisaje humano de pueblos y ciudades, feministas o militantes de izquierda que rompen unos consensos opresores, pero aceptados durante décadas, pobres que generan odio porque rompen también con la imagen pacífica del espacio público que fabrican los medios de comunicación. Estos movimientos inventan la sociedad del pasado y proponen recuperarla a través de la lucha contra aquel enemigo migrante, feminista o pobre. Los instrumentos que tienen, especialmente los comunicativos, son potentes armas que construyen temor, estereotipos y falsas noticias que, como hace cien años sucedía con el africano, inventan nuevos enemigos a partir de discursos que ocultan los conflictos sociales y económicos" (Aragoneses, 2019, p. 125).

8 Cabe notar que en los últimos años algunos de estos movimientos de la nueva derecha han defendido los derechos del colectivo LGTBIQ como parte de la reivindicación de los 'valores republicanos occidentales' amenazados por los extranjeros miembros de otras culturas como el islam. Quizás el ejemplo más destacado al respecto es el de Rassemblement National de Marine Le Pen, aunque esta postura es común en los países noreuropeos, donde, además, las luchas feministas se desestiman porque la igualdad ya habría sido lograda (Mudde, 2021). 9 Este rechazo al movimiento LGTBIQ no es exclusivo de las derechas. Basta recordar los encendidos discursos de Rafael Correa contra la 'ideología de género', y de Evo Morales, patologizando la homosexualidad, etc.
} 
lo que resalta el rol de la familia tradicional y los embates contra los movimientos LGBTTIQ, la llamada ideología de género y el feminismo, haciendo hincapié en rechazos frente a la interrupción del embarazo, la identidad de género o la educación sexual. El segundo de ellos [...] es la exacerbación de la libertad de mercado: la falta de empleo se explica por las altísimas presiones tributarias y los Estados paternalistas omnipresentes. Es necesario hacer brutales ajustes fiscales, despedir a la mayoría de los empleados públicos y privatizar todo aquello que aún esté en manos del Estado. No es casual que en ambas direcciones los términos "comunista" o "marxista" sean considerados como un insulto (Dvoskin, 2019, p. 164) ${ }^{10}$.

Estas nuevas derechas están muy claramente representadas en movimientos sociales tales como HazteOír/CitizenGo en España o "Con mis hijos no te metas", surgido en Perú a fines del 2016 contra la inclusión del género en el currículo, el cual se expandió cuan mancha de aceite por todo el mundo hispanoparlante. Tal movimiento denuncia una 'ideología de género' que busca desestabilizar la familia heteroparental, con la finalidad de instaurar un 'nuevo orden mundial' — liderado por figuras como Bill Gates y George Soros-, que promueva la homosexualidad, el aborto, el cambio de sexo, el matrimonio homosexual, y el control de la población ${ }^{11}$. Asimismo, encontramos estas teorías conspirativas en grupos de la (ultra)derecha alternativa como el movimiento QAnon, partícipe destacado del asalto al capitolio estadounidense del 6 de enero del 2021. Este grupo ha denunciado en las redes sociales la existencia de una supuesta red de pedofilia, promovida por parte del establishment político y cultural. Precisamente en este asalto - y en ese tipo de eventos en general - han tenido una presencia destacada desde grupos neonazis hasta 'libertarios', oponiéndose al socialismo que Trump denuncia en sus opositores demócratas ${ }^{12}$.

\footnotetext{
10 Cooper (2017) desarrolla con gran detalle para el caso estadounidense el vínculo entre la defensa de la moral tradicional, representada tanto por la familia heterosexual y blanca como por el mercado competitivo neoliberal, y el ataque al welfare.

11 De hecho, la Universidad del Central Europea, financiada por Soros y que incluye en su currículo los estudios de género, debió abandonar Hungría por la presión del gobierno de Viktor Orbán.

12 Cabe notar que, en casos como el de Europa Central y Oriental, el rechazo a la ideología de género puede ser una forma de organizarse contra el establishment neoliberal, que le exige a las mujeres participar igualitariamente en el mercado de trabajo sin brindar derechos económicos y sociales que puedan facilitar el trabajo reproductivo (Zacharenko, 2019).
} 
En referencia a las mujeres, la ultraderecha actual oscila entre un 'sexismo benévolo', propio de la derecha tradicional, que las venera en cuanto madres, responsables de criar a los hijos moral y físicamente, y un 'sexismo hostil' que:

[...] cosifica y degrada a las mujeres, a las que tiende a caracterizar como enemigas empeñadas en controlar a los hombres por medio de la ideología feminista o de la seducción sexual. Si el sexismo benévolo ve a las mujeres como criaturas moralmente puras y físicamente débiles, el sexismo hostil las considera moralmente corruptas y políticamente poderosas (Mudde, 2021, s/p).

Mientras en el primer caso la violencia contra las mujeres en el plano político era mal visto, ahora asistamos a ataques misóginos violentos por motivos políticos, como en el caso de ciertos involuntarily celibates (Incels) ${ }^{13}$. Según Mudde (2021), el sexismo benévolo predomina en la derecha radical populista, en tanto que el hostil lo hace en la derecha alternativa, aunque lo más frecuente es la mezcla entre ambos. Sin embargo, "[...] casi todos los grupos de ultraderecha tienen un concepto negativo del feminismo contemporáneo"(Mudde, 2021). Muchos grupos ultraderechistas caracterizan al feminismo y la homosexualidad como una amenaza a la nación, ya que socavan la familia tradicional y son vistos como ajenos a la cultura nacional (Mudde, 2021).

Para comprender algunos aspectos de la cosmovisión de estas nuevas derechas, tomaremos como ejemplo de esta cruzada contra la ideología de género como punta de lanza del comunismo a El libro negro de la nueva izquierda. Ideología de género o subversión cultural, de Agustín Laje y Nicolás Márquez (2016). En este texto, de gran difusión en Latinoamérica, Laje y Márquez, quienes se piensan a sí mismos como los intelectuales que le faltaban a la derecha, sostienen que la ideología de género subdividida en feminismo, abortismo y homosexualismo cultural- es una pantalla del neomarxismo. Señalan que, en 1992, mientras las fuerzas anticomunistas festejaban el fin de la historia, el comunismo se renovaba a través de los movimientos indigenistas, feministas y ecologistas; y de ese

13 Se trata de machos beta o perdedores en la competencia por las mujeres, que, entre otras cosas, acusan al feminismo de haberles quitado el derecho a disponer del cuerpo de las mujeres. Si bien esta misoginia se desarrollaba en foros de Internet, en los últimos años se han registrado asesinatos de mujeres por parte de miembros de estos grupos. 
modo el pensamiento de izquierda se volvió de a poco hegemónico. En la explicación de los autores, las estructuras de izquierda tuvieron que fabricar ONG y reacomodar sus consignas y fuentes de financiamiento frente a la desaparición de la uRss. No obstante, mantuvieron su esencia comunista, subversiva e incluso totalitaria:

Silenciosamente, la izquierda reemplazó así las balas guerrilleras por papeletas electorales, suplantó su discurso clasista por aforismos igualitarios que coparon el extenso territorio cultural, dejó de reclutar “obreros explotados" y comenzó a capturar almas atormentadas o marginales a fin de programarlas y lanzarlas a la provocación de conflictos bajo excusas de apariencia noble, las cuales prima facie poco o nada tendrían que ver con el stalinismo ni mucho menos con el terrorismo subversivo, sino con la "inclusión" y la "igualdad" entre los hombres: indigenismo, ambientalismo, derecho-humanismo, garantoabolicionismo e ideología de género (esta última a su vez subdividida por el feminismo, el abortismo y el homosexualismo cultural) comenzaron a ser sus modernizados cartelones de protesta y vanguardia (2016, p. 18).

En este libro, que recuerda a los manuales de contrainsurgencia editados por el Estado Mayor del Ejército Argentino en los setenta (1976, $1977)^{14}$, los autores dejan entrever que el enemigo comunista nunca puede ser subestimado, porque jamás se presenta como lo que es. Por el contrario, se oculta, realizando una guerra psicológica para desmoralizar al 'mundo libre 'mediante organizaciones colaterales que existían antes de la URss, "[...] y siguieron existiendo después de la extinción de la misma" (Laje \& Márquez, 2016, p. 8). Los objetivos concretos de los movimientos ecologistas, de defensa de derechos humanos, feministas, indigenistas, etc., serían aparentes, puesto que en realidad responderían a la avanzada comunista. Detrás de la bandera multicolor del movimiento LGTBIQ, de las banderas verdes del ecologismo o de la wiphala se escondería la bandera roja con el martillo y la hoz. De este modo, el variopinto mosaico de movimientos sociales que surgió en las últimas cuatro décadas se

14 Esta similitud no es, quizás, pura coincidencia, si tenemos en cuenta que los autores, defensores del terrorismo de Estado, fueron becados para estudiar "[...] tácticas de contraterrorismo en la Universidad de la Defensa, en Washington, donde se formaron varios cuadros militares del Pentágono" (Elman, 2018, s/p). 
dividiría en marxistas conscientes e idiotas útiles, categoría en la cual entrarían las personas neutrales o indiferentes, las cuales, con su inacción, favorecen el avance de la subversión. Por esto, los autores se proponen desenmascarar a la nueva izquierda en todas sus facetas, empezando por la 'ideología de género', a la que consideran una de las principales pantallas del neomarxismo el cual, al no encontrar asidero en la lucha de clases, ha pasado a la batalla cultural como terreno decisivo de disputa por la hegemonía ${ }^{15}$.

La estrategia de Laje consiste en separar un feminismo humanista y liberal de la primera ola, que luchaba de manera respetable por los derechos civiles, políticos y educativos de las mujeres, de un abominable feminismo socialista, el cual vendría luego, inspirándose en las ideas engelsianas que sostienen un origen conjunto de la propiedad privada y la familia patriarcal. Si los problemas planteados por el feminismo liberal podían resolverse "[...] introduciendo reformas electorales y educativas[, el marxista] solo puede resolver la cuestión con arreglo a una revolución violenta que acabe con la propiedad privada y con la familia como institución social, pues aquí se halla el germen del mal” (Laje \& Márquez, 2016, p. 38).

Ahora bien, este feminismo marxista no se limita a reclamar la igualdad entre hombres y mujeres, nunca lograda en los estados socialistas; deriva enla horrorosa ‘ideología de género', contraria a cualquier idea de naturaleza. De hecho, los autores suscriben plenamente y retoman como inspiración una advertencia hecha por Ludwig von Mises en 1922 en el marco de una "cruzada heroica contra el socialismo", que algunos libertarios incautos ${ }^{16}$, funcionales al "neomarxismo culturalmente hegemónico", no estarían teniendo en cuenta hoy:

15 Cabe notar que el propio libro de los autores formaría parte de esta batalla cultural por la hegemonía intelectual y moral. Esta adopción de cierta lectura de Gramsci para la promoción de la derecha encuentra un antecedente en la Nouvelle Droite francesa de los setenta, bajo la égida de intelectuales como Alain de Benoist quien, a diferencia de Laje y Márquez, es un referente de la corriente social-identitaria. Por lo demás, Laje se declara admirador de Laclau, quien revitalizó en las últimas décadas al pensamiento político de la hegemonía (Elman, 2018).

16 Así afirma Márquez: "En fin, ya es sabido desde hace tiempo que los libertarios de ahora no tienen mucho que ver con los liberales históricos. Es decir con aquellos cruzados que en un mundo signado por el totalitarismo defendían la libertad individual a capa y espada sin por ello perder de vista que existen limitaciones y condicionamientos razonables a la misma (tanto sea por impedimentos del orden natural como de la propia vida en comunidad)" (2016, p. 204). En efecto, los autores son afines al paleolibertarismo, al estilo de Murray Rothbard, quien conjuga, desde los años setenta, una defensa del Estado mínimo con una visión reaccionaria y autoritaria que critica abiertamente a los conservadores por haber adoptado la visión de sus enemigos. Para un análisis de esta figura, véase Stefanoni (2021) 
Mientras el movimiento feminista se limite a igualar los derechos jurídicos de la mujer con los del hombre, a darle seguridad sobre las posibilidades legales y económicas de desenvolver sus facultades y de manifestarlas mediante actos que correspondan a sus gustos, a sus deseos y a su situación financiera, sólo es una rama del gran movimiento liberal que encarna la idea de una evolución libre y tranquila. Si, al ir más allá de estas reivindicaciones, el movimiento feminista cree que debe combatir instituciones de la vida social con la esperanza de remover, por este medio, ciertas limitaciones que la naturaleza ha impuesto al destino humano, entonces ya es un hijo espiritual del socialismo. Porque es característica propia del socialismo buscar en las instituciones sociales las raíces de las condiciones dadas por la naturaleza, y por tanto sustraídas de la acción del hombre, y pretender, al reformarlas, reformar la naturaleza misma (Mises, citado por Laje \& Márquez, 2016, p. 35) ${ }^{17}$.

Ahora bien, lo que Laje entiende por tercera ola del feminismo, la ‘ideología de género', no sería tanto un desarrollo autónomo del pensamiento feminista occidental, sino más bien el resultado de una estrategia de la KGB para lavar el cerebro de las nuevas generaciones de norteamericanos con el afán de desmoralizar y desestabilizar a las potencias occidentales. Para dar sustento a esta tesis conspiranoica, que además presupone a un público falto de entendederas, al igual que para criticar el papel de la mujer en la uRss se basa en... jla opinión de

\footnotetext{
17 En el caso argentino encontramos al interior de los discursos liberales tendencias que aparecen entrelazadas con la defensa del neoliberalismo, pero desde plataformas culturales distintas y a veces contradictorias. Por un lado, podemos identificar en los partidos mayoritarios sectores de un 'neoliberalismo progresista' (Fraser \& Senkara, 2019), amigable con algunas reivindicaciones feministas como el derecho a la interrupción voluntaria del embarazo, y de un neoliberalismo conservador. Por otro lado, están quienes se definen como libertarios, divididos en liberales, minarquistas y anarco-capitalistas. En teoría ellos deberían ser indiferentes, cuando no favorables, a la 'ideología de género' o al aborto, pero se oponen a ellos por razones pseudoeconómicas ("el Estado no tiene que pagar abortos con la plata de todos" - aunque un parto cueste mucho más dinero que un aborto seguro-), mientras que contradicen la implementación de la Ley de Educación Sexual Integral porque no puede haber un currículo único obligatorio en materia de educación sexual. Este grupo se suele mezclar con una 'derecha ultramontana' que tiene su eje en la defensa de la propiedad privada, la familia occidental y cristiana, la lucha contra el aborto, sazonada con una agenda ultraliberal en lo económico. Esto último se relaciona de manera más clara con el proceso de reorganización nacional al que algunos de ellos reivindican. Laje y Márquez forman parte de esta última tendencia, que se ha fortalecido con la campaña 'provida', financiada por sectores católicos y evangélicos. Tampoco hay que olvidar que existe una extrema derecha antiliberal, con sectores neonazis, que tiene una trayectoria política tan dilatada como escasa representación político-electoral. No obstante, se ha sumado a movilizaciones de la derecha liberal, ya que coinciden en la defensa del patriarcado y el anticomunismo.
} 
un desertor de la KGB publicado en Youtube ${ }^{18}$ ! Prueba de esto sería que desde los sesenta no hubo una producción de un nuevo pensamiento feminista en la URss ni una tolerancia hacia este. Pero lo más llamativo es que esta tesis implica que, desde hace décadas, todos los espacios de poder en Estados Unidos son ocupados por sujetos 'contaminados' por esta ideología. Siguiendo este razonamiento, se deberían haber generado cambios en las instituciones políticas y económicas a favor del marxismoleninismo (Laje \& Márquez, 2016, p. 50) ${ }^{19}$.

Así, del 'feminismo marxista' se pasa directamente al 'feminismo culturalista', 'radical' o 'neomarxista', que para los autores es una tercera ola, responsable de la germinación de la ‘ideología de género’. Esta encontraría su origen en $\mathrm{El}$ segundo sexo de Simone de Beauvoir, texto que Laje y Márquez consideran el libro más importante del feminismo del siglo xx. De ese modo, se probaría que "la ideología de género tiene su origen y desarrollo en el seno de la ultraizquierda” (Laje \& Márquez, 2016, p. 82). Desplaza así la disputa hegemónica de lo económico a lo cultural, para destruir "[...] la superestructura — moral, religiosa, ideológica, jurídica, familiar-vigente” (Laje \& Márquez, 2016, p. 82).

Este marxismo cultural invierte el orden causal del marxismo clásico. Ya no serían los cambios en las relaciones de producción las que influyen en las formas de vida. Por el contrario, hay que modificar las formas de vida para cambiar los sistemas políticos y económicos. En ese marco:

[...]la idea de género, como algo independiente del dato natural, es exacerbada como estrategia para destruir las instituciones sociales que serían funcionales al capitalismo: la familia monogámica, la prohibición del incesto y la pedofilia, la heterosexualidad, etcétera. De aquí se levanta el puente existente entre esta tercera ola feminista, deconstructiva y culturalista, y lo que en los años 90 empezó a conocerse como "teoría queer" (Laje \& Márquez, 2016, p. 61).

Según Laje (2016), el feminismo no sirve a las mujeres, sino a la "revolución cultural izquierdista". Alejándose de sus nobles orígenes liberales y sufragistas, el marxismo cultural estableció una homología

18 El desertor en cuestión es Yuri Bezmenov y la entrevista se encuentra en https://www.youtube. com/watch? $=\mathrm{d} 18 \mathrm{Hy} 5 \mathrm{U}$ ouN8

19 Nótese que esto fue publicado el mismo año en que Donald Trump fue elegido como presidente de los Estados Unidos, alguien que tiene muchas afinidades ideológicas con los propios autores. 
entre la lucha de clases y la de los sexos, en la cual la liberación de la sexualidad y la ruptura de las superestructuras sociales y morales serían la clave para destruir al sistema. La 'ideología de género', con su deconstrucción de la propia noción de naturaleza humana, es el epítome de esta tendencia, para los autores estudiados.

Junto al abortismo y el feminismo, la 'ideología de género' promovería el 'homosexualismo cultural', lo cual Márquez (2016) aborda. Para que no se lo acuse de intolerante, nos aclara:

\section{[...] distinguiremos siempre entre quien padece una tendencia} homosexual inculpable (que merece todo nuestro respeto), de aquel que se dedica al proselitismo militante o ideológico al servicio de la expansión y consolidación de una agenda que hoy presta fiel asistencia a la reciclada causa comunista (Laje \& Márquez, 2016, p. 110, énfasis propio) $)^{20}$.

Al igual que el feminismo, los homosexuales también estarían siendo usados como marionetas para una causa que les es ajena por parte de un sector que hasta hace poco los hubiese castigado severamente - si tomamos los antecedentes de los e stados socialistas del siglo $\mathrm{xx}$ -

Como vemos, reeditando viejos esquemas, la acusación de feminazismo va de la mano al temor del femi comunismo. Si bien es imposible saber cuánto hay de estrategia retórica y cuánto de efectivo temor a que el feminismo destruya al capitalismo hetero-patriarcal, no caben dudas de que entre estos pensamientos y movimientos reaccionarios y los feminismos hay una frontera antagónica que tiene que ver con una disputa por el papel de las subjetividades feminizadas en la sociedad neoliberal. Como señala Nuria Alabao, en todos los países, “[...] el feminismo constituye uno de los mayores frentes contra el avance del neofascismo, tanto en el voto, como en la calle" (Alabao, 2019, p. 193). Mientras que el feminismo mira al futuro, la derecha radical, como señala Traverso (2016), busca restaurar un pasado imaginario, en el cual las clases, las razas y los sexos vivían en una armonía basada en la aceptación

\footnotetext{
20 La palabra 'padecer' no es inocente, ya que el autor sostiene, a lo largo de su trabajo, que la homosexualidad, a la que a veces prefiere llamar con el bíblico y preclínico mote de 'sodomía', es una patología curable, que conduce a múltiples enfermedades, especialmente venéreas. Según esa posición, si la psiquiatría y el psicoanálisis han abandonado esta postura, no es por una revisión reflexionada de sus presupuestos normalizadores, sino, pura y exclusivamente, por la presión política del lobby homosexualista.
} 
de las jerarquías 'naturales'. El antifeminismo rechaza la autonomía de las mujeres porque esa lucha amenaza con destruir las jerarquías existentes en la sociedad y, especialmente, porque "[...] el feminismo ataca de raíz la división sexual del trabajo que está en la base de todo el resto de las desigualdades que se producen entre los géneros" (Alabao, 2019, p. 193)

En un sentido concomitante, Wendy Brown (2019) entiende la cruzada antifeminista y el auge de la extrema derecha como parte de una política del resentimiento, generada por los efectos del neoliberalismo en la economía y en el destronamiento de la masculinidad blanca. Hay una doble humillación de raza y clase, en un marco nihilista en el que la voluntad de poder y la búsqueda del placer ya no son sublimados. Esta situación provoca un tipo de resentimiento que ya no surge de la debilidad, como en el análisis nietzscheano de la moral judeocristiana, sino de la pérdida de privilegios de raza, género y clase. Esto habilitaría dos posibilidades. En primer lugar, se presenta un rencor que no puede sublimarse y ocasiona una política permanente de venganza, de ataque a quienes son tenidos por responsables del destronamiento de la masculinidad blanca: "[...] feministas, multiculturalistas, globalistas, quienes a la vez los desbancan y los desdeñan” (Brown, 2019, p. 177, traducción propia). La segunda posibilidad sería es que el resentimiento por la pérdida de privilegios posibilite la emergencia de una nueva escala de valores, que denuncia la igualdad y el mérito para afirmar una supremacía basada exclusivamente en el derecho tradicional. Este nihilismo exacerbado por la crisis de la dominación blanca y masculina genera un giro apocalíptico, según el cual, “[...] si los hombres blancos no pueden ser los dueños de la democracia, no habrá democracia. Si los hombres blancos no pueden gobernar el planeta, no habrá planeta” (Brown, 2019, 180, traducción propia).

En este contexto, el combate a la ‘ideología de género’ va más allá de la tradicional oposición católica a los derechos sexuales y reproductivos de las mujeres y del colectivo LGTBIQ, para incluir “[...] el matrimonio homosexual, las políticas de igualdad, e incluso contra los estudios de género en los ámbitos académicos y la educación igualitaria en las escuelas” (Alabao, 2019, p. 201). Esa cruzada obedece a que el “[...] feminismo más radical pide reorganizar toda la sociedad sobre bases nuevas: en torno a la cuestión de la reproducción social de la vida, puesta seriamente en riesgo por el capitalismo financiero. Es decir, a partir de las relaciones de interdependencia, que son el verdadero fundamento de lo social” (Alabao, 2019, p. 203). 
En efecto, el antagonismo en cuestión no puede reducirse a factores económicos ni "meramente culturales". En ese sentido, el planteamiento de Alabao muestra que el feminismo invierte de alguna manera lo señalado por Laje y Márquez (2016), tomando como programa lo que ellos toman como premisa. Si para estos autores el feminismo y las luchas culturales son una fachada de la lucha de clases y del marxismo, para el feminismo anticapitalista la "batalla cultural" debe poder visibilizar el vínculo entre el control sobre las subjetividades feminizadas y la explotación del trabajo reproductivo, luchando contra el capitalismo financiero y sus consecuencias. Para esto, debe buscar respuestas en el futuro, y no, como hace la derecha radical, en el pasado.

\section{LOS FEMINISMOS: ¿EL MARXISMO DEL SIGLO XXI?}

Si bien nos parece burda la hipótesis de que el feminismo y la 'ideología de género' son epifenómenos de un marxismo que, ante el fracaso de la lucha de clases, se vuelca a la batalla cultural, debemos reconocer que la derecha antifeminista parece haber entendido esta ligazón entre feminismo y marxismo - y entre feminismo y anticapitalismo- mucho mejor que algunos sectores de izquierda, que dejan en segundo lugar la problemática de la reproducción social. En ese marco, nos preguntamos: ¿qué hay en el feminismo que lo hace tan peligroso para el orden vigente y lo acerca al comunismo e incluso al marxismo? Para responder respecto de este vínculo, debemos considerar que ambas corrientes no solo han dialogado a lo largo de los siglos xx y xxi, sino que ambas buscan comprender las relaciones de poder y de dominación que nos sujetan y explotan, para transformarlas (Arruzza, 2010).

En ese sentido, así como los marxismos a lo largo del siglo xx se propusieron actualizar el diagnóstico de Marx sobre el capitalismo, la lucha de clases, el sujeto revolucionario y el comunismo, ciertos feminismos lo hacen también desde los años setenta con la intención de teorizar la relación material que existe entre capitalismo, colonialismo y hetero-patriarcado. Estos feminismos han realizado acalorados debates tanto hacia adentro como hacia afuera de sus movimientos; además, han acordado y disentido con otras teorías revolucionarias. Pero, sin lugar a duda, el marxismo ha sido una de las tradiciones centrales con las que han producido sus debates y combates, sus herencias y críticas. Cavilar sobre 
esta relación es sumergirnos en una historia compleja de pensamientos y prácticas políticas que se entrecruzan, disputan y contaminan.

Para acercarnos a una teoría materialista feminista, es decir, para comprender su herencia marxista, debemos rastrear no tanto las diferencias entre estos movimientos como sus similitudes, tal como lo hace el pensamiento político de derechas. Tanto el marxismo como los feminismos pueden ser comprendidos como pensamientos de la crisis y de la crítica al estado de cosas existente, dado que ninguno se encuentra desvinculado de las coyunturas político-económicas concretas. Teoría y práctica son inseparables tanto para ciertos feminismos como para ciertos marxismos.

Por esto, podemos considerar a estos feminismos, como hace Sazbón (2002), junto con el marxismo, como teorías de la praxis. Esto supone que ninguno puede pensarse como movimientos cerrados, sino que siempre se debe especificar desde qué feminismos o marxismos estamos hablando, qué debates queremos resaltar, o a qué momento histórico y territorialidad nos estamos refiriendo. Esto implica comprender también, que si entendemos a los feminismos - anticapitalistas - como parte de las teorías críticas (Fraser, 2008), para cada momento histórico podríamos definir qué feminismos se han vuelto hegemónicos y cuáles han resistido desde los márgenes. En este sentido, en cada época de los feminismos que analicemos encontraremos una relación entre las transformaciones del sistema capitalista, las luchas y sus formas organizativas. Sean estas luchas por la emancipación o el cuestionamiento del paradigma hegemónico de cada momento — por ejemplo, el de los feminismos negros como una impugnación a los intentos totalizantes y universalizantes de los feminismos blancos (Lorde, 2002) - . Estos procesos han desembocado en una posterior reformulación o por lo menos en un debate teórico-práctico de los feminismos.

Con el devenir neoliberal del capitalismo, uno de los debates principales de los feminismos comienza a centrarse en la articulación entre capitalismo, patriarcado y colonialismo a través de una relectura del marxismo y una revisita a la problemática de la reproducción social y de la relación reforma-revolución. Más específicamente, se profundiza un interés por comprender cómo las transformaciones sufridas en el modo de acumulación capitalista a partir de la década del setenta y sus reconfiguraciones neoliberales han impactado en el mundo del trabajo (nos referimos al paso de una acumulación fordista a una posfordista o flexible). Se produce una metamorfosis social signada por la flexibilidad 
y precariedad tanto en el mundo del trabajo como en los mercados laborales, en las instituciones, en las subjetividades y en los patrones de consumo. Fenómenos que implican preguntar cómo estas mutaciones han impactado en la composición del sujeto revolucionario y los debates respecto a la revolución y las transformaciones democráticas. De este modo, los feminismos nos invitan a reflexionar sobre un proceso, como la reproducción social, que atraviesa los flujos de la valorización de capital, las formas de vida y la producción de subjetividades de un capitalismo contemporáneo, que se encuentra particularmente hegemonizado por las finanzas, la precariedad de la vida y una crisis de la condición salarial.

Estos procesos se profundizan en Sudamérica a partir de la crisis de los gobiernos progresistas y el avance de una derecha explícitamente neoliberal y neoconservadora, y al atravesar la pandemia mundial del covid-19. En ese sentido, la coyuntura en la que escriben autores como Laje y Márquez está marcada, por un lado, por el antagonismo entre los feminismos críticos latinoamericanos y las nuevas derechas, y, por el otro, por las múltiples posturas, tanto teóricas como prácticas, que se van poniendo en movimiento en los propios feminismos respecto al problema del sujeto y de la revolución. En otras palabras, se pregunta sobre cuál es el sujeto de los feminismos y respecto al carácter reformista o revolucionario de los gobiernos progresistas y de los propios feminismos. Ahora bien, si, según nuestra hipótesis, el feminismo, al igual que el comunismo, busca abolir y superar el actual estado de cosas, ¿cómo caracterizar a este último?

\section{EL ESTADO DE COSAS EXISTENTE: EL CAPITALISMO PATRIARCO- COLONIAL Y EL CONTROL DE LA REPRODUCGIÓN BIOSOCIAL}

Los debates teórico-políticos sobre la reproducción social abren, dentro del movimiento feminista, tres grandes cuestiones interrelacionadas. En primer lugar, debaten el vínculo entre capitalismo, colonialismo y patriarcado, si es unívoca o interseccional, etc. En segundo lugar, preguntan quién es el enemigo principal de los feminismos (Delphy, 1985). En tercer lugar, indagan sobre la capacidad de producir valor del trabajo reproductivo, y, por ende, interroga por la composición del sujeto revolucionario. Es decir, la problemática de la reproducción social 
interpela sobre la producción social capitalista de la diferencia en términos de clase, raza, sexo, género, edad, etc.; piensa las diversas y complejas formas político-organizativas de las resistencias con sus múltiples antagonismos, y hace vigente la pregunta por la materialidad abstracta y directamente social del capital y sus relaciones en cuanto totalidad.

Si bien no podemos extendernos en estos debates, aquí pretendemos indagar sobre los feminismos que centran sus análisis en la feminización de la conexión capital/trabajo y la vinculan de primera mano a un problema clasista, racial y migratorio, en el cual las discusiones sobre la reproducción biosocial y una relectura del marxismo se vuelven clave. Estos feminismos, atentos a las mutaciones de la relación entre capitalismo, patriarcado y colonialismo, reformulan y debaten las categorías de su propia tradición, así como redefinen sus prácticas políticas y organizativas, sin perder el horizonte anticapitalista de la lucha.

Estos feminismos encuentran en el pensamiento marxista, más precisamente en una relectura de Marx, algo fundamental para heredar. En esta relación se resalta la capacidad para generar un movimiento crítico y la posibilidad de abolir al estado de cosas existente. Más en concreto, estas producciones feministas se sostienen sobre la recuperación crítica del método materialista y dialéctico, que Marx presentó en su análisis sobre el capitalismo — como una totalidad socioeconómica y cultural-. Se busca con esto precisar la relación entre neoliberalismo, colonialismo y patriarcado, no como mera sumatoria de opresiones, sino como un conjunto complejo. En este proceso los modos de explotación, opresión, alienación y extracción se funden en una contradicción entre la reproducción social de la producción de capital y la sostenibilidad de la vida. Esto en el neoliberalismo se materializa como una crisis civilizatoria, de reproducción social y de cuidados (Pérez Orozco, 2014; Rodríguez Enríquez, 2015; Quiroga Díaz, 2009; Svampa, 2015).

Si la crítica de Marx a la economía política mostraba una morada oculta en la producción social y en las relaciones sociales que esta genera en el capitalismo, que son veladas a través de un mecanismo en el que el mercado es productor de valor, los feminismos descienden hacia la morada oculta de la reproducción. Sumergirnos en esta hace evidente que, por un lado, en la producción opera una división sexual e internacional del trabajo. Esta se sustenta muchas veces en una diferencia de salario a pesar de que se haga una misma tarea, esto es, en una explotación mayor del trabajo femenino y racializado (aumento de extracción de plusvalía) respecto del trabajo masculino y blanco. También se feminizan 
y racializan determinados tipos de trabajo que son desvalorizados frente a otros (Federici, 2015; Mies, 2018; Bidaseca, 2015). Por otro lado, si Marx nos advierte que, en el sistema capitalista, la reproducción de la fuerza de trabajo está ligada a la capacidad de subsistencia de lxs trabajadorxs en un determinado momento histórico y ese es su valor (Marx, 2002), surge la pregunta de quién realiza este trabajo — fundamentalmente feminizado o racializado-, y por qué el trabajo que garantiza la reproducción de la fuerza de trabajo no es remunerado ni reconocido, o se realiza en situaciones de mayor precariedad y flexibilización que el trabajo considerado productivo (Pérez Orozco, 2014; Quiroga Díaz, 2009; Lorey, 2016; Federici, 2013). El trabajo reproductivo, al estar principalmente feminizado y racializado, se construye como natural y somete a múltiples formas de violencia social legitimada (Segato, 2016; Preciado, 2008; Rolnik, 2015; Falquet, 2017). A la par, el trabajo reproductivo garantiza socialmente el sustento de la eterna capacidad de trabajar, y, por tanto, la misma vida en la amalgama de la acumulación de capital.

Entonces, la pregunta feminista por la reproducción biosocial plantea dos cuestiones centrales para pensar la materialidad del capitalismo patriarco-colonial. Por un lado, interroga por el estatuto de productoras de valor de las relaciones sociales más allá del trabajo asalariado en general y fabril en particular. Es decir, no solo indaga por el proceso de valorización capitalista del trabajo asalariado en áreas comprendidas como no productivas: también cuestiona la exclusividad del salario como la relación central en la valorización de capital. Por el otro, cuestiona una historización evolucionista del capitalismo — disputando la distinción entre zonas desarrolladas y subdesarrolladas - Posibilita un debate sobre la especificidad de las relaciones capitalistas, al cuestionar la centralidad de la producción ampliada del capital frente al trabajo no asalariado, informal, reproductivo, la acumulación por desposesión y los métodos violentos de extracción de valor.

Para estos feminismos la reproducción ampliada y 'pacífica' del capital se ha podido erigir en un momento histórico específico del capitalismo, en un espacio determinado y para un tipo específico de trabajadores, sobre el desarrollo de un capitalismo imperialista que a fuego y sangre negó el carácter de trabajadores de múltiples formas de trabajos sin derechos y no necesariamente mediados por la relación salarial, y sobre la insistencia de una izquierda teórica y militante que ha relegado la lucha de estos sectores a un segundo plano, como un fenómeno 
meramente cultural ${ }^{21}$ (Butler, 2007). La acumulación por despojo corre por los carriles subterráneos y silenciosos de un capitalismo que la tiene como parte central de su producción de ganancias y de su proceso reproductivo. Cuerpos racializados, migrantes, sexuados y generizados son re-producidos como componentes de los 'recursos naturales' que el capital explota, domina y destruye, en muchos casos de modo gratuito. Por lo tanto, esta diversidad de cuerpos y subjetividades se producen como territorios explotados y despojados por la acumulación capitalista.

La relación entre seres humanos, naturaleza y tecnología redefine sus límites y determinaciones. Para estos análisis feministas, la explotación sobre los cuerpos feminizados y racializados es similar a la que se genera sobre la naturaleza en cuanto son producidos como recursos que el capital extrae y utiliza hasta su agotamiento. De este modo, tanto la producción destructiva y contaminante de la técnica como la producción de una necropolítica del capital sobre determinados cuerpos, muestran que las fuerzas productivas del capitalismo son en primer término destructivas (Valencia, 2016). Al realizar esta afirmación, estos feminismos comprenden que existe una relación sobredeterminada entre la máquina de guerra social del capital y la máquina técnica de la producción tecnológica de capital fijo (Lazzarato, 2020). Es decir, estos movimientos rompen con el productivismo reinante de los análisis marxistas, en los cuales primaba una lectura positiva del desarrollo capitalista, que se desplegaba como necesario e independiente de la lucha de clases. Por el contrario, sostienen que la producción técnica del capital es, antes que nada, una máquina de destrucción de cuerpos, subjetividades y naturaleza de modo diferencial, pero global, en el proceso de producción y acumulación de capital.

De esta manera, con el desarrollo capitalista no hay ni superación del patriarcado ni condiciones técnicas específicas que determinen objetivamente el momento revolucionario . Por el contrario, se presenta un sistema destructor de 1 proceso de reproducción en el devenir de su valorización, puesto que produce también para la muerte parte de su capital variable, de su "fuerza productiva " fundamental, la clase

\footnotetext{
21 Acá hacemos referencia a ciertos sectores tradicionales de las izquierdas, sobre todo partidarias e intelectuales, que no reconocen el lugar relevante de los trabajos reproductivos, en los procesos de valorización, principalmente en lo referente a los gratuitos, hogareños, de cuidados y feminizados. Entendemos, por otro lado, que si bien cierta izquierda ha problematizado la noción de ‘trabajo asalariado' a partir del análisis de trabajos no mediados por una relación salarial —fundamentalmente en el sector servicios, como Glovo, Pedido ya, etc.—, lo hacen principalmente porque los consideran parte del sector productivo y, por tanto, generadores de valor en términos capitalistas.
} 
trabajadora - generizada y racializada - en cuanto que trabajo vivo. Por lo tanto, estos feminismos re-politizan espacios y relaciones sociales al reinsertarlas en la estructuración y modulaciones subjetivas capitalistas y en los procesos de valorización de capital. La materialidad de la defensa capitalista de la propiedad privada se amplía hasta múltiples modos de trabajo que atraviesan la esfera de lo íntimo - lo sexual, genérico y racial-, las estructuras familiares e intersubjetivas. Las produce de modo diferencial, haciendo de esas diferencias de formas de trabajo y producción de subjetividades el modo de la acumulación de ganancia ensamblada a una lógica de valorización abstracta de capital que es ya directamente social (Mezzadra, 2017).

\section{LA MAREA FEMINISTA: EL MOVIMIENTO QUE TRANSFORMA EL ESTADO DE COSAS EXISTENTE}

Para estos feminismos, es necesario problematizar los modos de producción de valor en el capitalismo patriarco-colonial. Esto no solo se hace enfatizando una teoría de la división socio-sexual-racial e internacional del trabajo, sino también en su incesante relación con la reproducción continua de la sociedad mediante procesos de acumulación de capital y producción mercantilizada de subjetividades y fuerza de trabajo. Destacan, por un lado, la importancia de visibilizar toda una serie de trabajos, vínculos y violencias que se ocultan y se reproducen en una rotunda división sexual del trabajo - que tiene sus particulares momentos pasibles de ser historizados (Federici, 2018, Fraser, 2015)—. Esta división sexual que naturaliza el papel de mujeres, feminizadas y racializadas, las produce como subjetividades responsables de sí, confinadas al mundo de las emociones —en contraposición a la razón—, con una determinada moral, comportamiento, sexualidad . Son cuerpos - reproductivosdeterminados biológica y fisiológicamente en el binarismo sexo-genérico hegemónico. De la misma manera, las trata de ciudadanas de segunda por ser propiedad tanto del Estado como de privados. Las reproduce como una fuerza de trabajo asignada a tareas reproductivas, trabajos gratuitos o mal pagos, domésticos, afectivos y de cuidados, que son desvalorizados social y monetariamente. 
Laje afirma: "[...] el feminismo parece servir cada vez menos a las mujeres y cada vez más a la revolución cultural izquierdista" (Laje \& Márquez, 2016, p. 89). No obstante, lejos de considerar a la relación sexual como una determinación biológica y natural, el feminismo la pone en jaque. De este modo, tanto desde las teorías queer como desde los feminismos materialistas y marxistas, varones y mujeres no son hechos biológicos, sino figuras o papeles socialmente determinados. En otras palabras, los sexos —y no solo los géneros- son reproducidos y configurados en un contexto biosocial. El enemigo principal de estos feminismos no es "el varón”, sino el patriarcado y su masculinidad hegemónica. Por tanto, el sujeto de los feminismos no son las mujeres en términos biologicistas. Antes bien, son las mujeres cis o trans, lxs trans y travas, las lesbianas, lxs intersex, etc., pues son figuras políticas antagónicas a la norma y al sistema como totalidad social. Desde Butler hasta Wittig se afirma que la heterosexualidad es un régimen político reproductivo. Este es un poderoso dispositivo ideológico que asegura y re-produce los papeles y las prácticas sexuales. Estos naturalmente se atribuyen a los dos géneros como un conjunto arbitrario de regulaciones inscritas en los cuerpos que aseguran la explotación material de un sexo sobre el otro. Cuestionar la naturalidad de la relación entre la masculinidad y la feminidad hegemónicas es poner en jaque ese patriarcado que los teóricos y militantes de las nuevas derechas desconocen en la teoría para sostener mejor en la práctica.

Por otro lado, estos feminismos nos advierten que el control patriarcal y la producción del trabajo feminizado y racializado son parte central de la lógica sistemática de capital y no pueden ser restringidos a un ámbito específico. De este modo, focalizar una perspectiva de la reproducción social permite llevar el análisis más allá de las nociones de cuidados y trabajo doméstico, al abarcar a la reproducción tanto de la vida como de las relaciones capitalistas patriarco-coloniales (Mezzadri, 2019). En otras palabras, ayuda a comprender tanto la reproducción de lxs trabajadorxs como de la fuerza de trabajo en el marco de determinadas condiciones de producción de valor y división social-sexual-racial e internacional del trabajo.

La reproducción capitalista es, para estos feminismos, directamente colonial y hetero-patriarcal. Tiene la particularidad, como afirma Luxemburgo (1968), de presentar ciclos de expansión que terminan en una crisis y en la gestión empresarial y estatal de estas. Por tanto, la reproducción, como fenómeno regular, es un problema completamente 
específico del capitalismo. En este, la producción individual no tiene para nada en cuenta las necesidades vitales de las sociedades, es decir la capacidad vital de su consumo, sino que es la ganancia, la extracción de un plusvalor, aquello que deviene central e ilimitado para la reproducción capitalista. De este modo, el capitalismo, además de perpetuar el proceso de reproducción, lo hace con una producción en escala creciente y con el aumento de la masa de plusvalía. La reproducción se vuelve una exigencia, deviene su condición de existencia. La baratura de las mercancías y su incesante producción es el principio del capital, y la fuerza de trabajo es la mercancía más peculiar de todas y central en este proceso.

Reducir los costos de la reproducción social — por parte del capitales parte imperante de su lógica acumulativa. Así, el incesante proceso de abaratar la mercancía fuerza de trabajo se traduce en una desvalorización de la reproducción social de lxs trabajadorxs, en tanto que genera una de las contradicciones centrales del capitalismo. La capacidad de consumo de estxs, garantía de su re-producción, es la condición de posibilidad de reproducir el capital. Al mismo tiempo, la reproducción en el capitalismo es siempre competencia. Por tanto, la reproducción de capital es para la empresa individual, dirá Luxemburgo (1968), la pérdida de la reproducción de otra, la reproducción de un Estado es a costa de las posibilidades de reproducción de otro, la reproducción de la fuerza de trabajo de unxs es a costa del trabajo reproductivo de otrxs. En definitiva, la reproducción ampliada de capital es siempre a costa de la desposesión de buena parte de la humanidad. Una parte que nunca es en general, sino que está socio racial y sexo-genéricamente producida, territorialmente construida y se encuentra internacionalmente dividida.

Entonces, para estos feminismos, lectores atentos de Luxemburgo, pensar esta doble y contradictoria relación de la reproducción biosocial en el capitalismo como problema regular y extendido es central para comprender la relación material entre capitalismo, colonialismo y patriarcado. Ahí se muestra el circuito que produce la mercancía “"más extraordinaria de todas", lxs trabajadorxs y sus múltiples modos de subjetivación. Sin embargo, como veíamos, este silencio de Marx puede ser leído de varias maneras, porque si bien se afirma como eje central que lxs trabajadorxs deben ser reproducidos en el capitalismo, el debate comienza en cómo analizar este proceso. Por un lado, se lo comprende a partir de la distinción marxista del valor, entre trabajo reproductivo como valor de uso y fuerza de trabajo como valor en la producción social. O sea, el proceso es una condición de posibilidad del trabajo productivo, pero no está 
integrado a este. Por lo tanto, estos feminismos proponen un análisis de los circuitos que reproducen a lxs trabajadorxs conectados, pero, al mismo tiempo, distintos a los del capital y la generación de valor. Por el otro, si el trabajo se vuelve mercancía bajo el capitalismo al hacerse una fuerza de trabajo, se debe a un trabajo pasado para poder producirse y reproducirse; lo necesita cada día para poder volver a trabajar o para venderse en el mercado. Entonces, la mercancía fuerza de trabajo 'esconde' trabajo objetivado en esta, y esa es una parte más que el capitalista absorbe como plusvalor y asume la forma de un trabajo feminizado, racializado, informal o gratuito - ya sea individual, colectivo o subvencionado por el Estado-.

Comprender a la fuerza de trabajo como una mercancía implica entenderla como proceso contradictorio donde se generan las capacidades —físicas, cognitivas, afectivas, etc. — necesarias en un determinado momento histórico, que producen los cuerpos y las subjetividades de lxs trabajadorxs. Esta mercancía, como cualquier otra, tiene un valor, porque tiene tiempo de trabajo objetivado; respecto a esta el capital intenta re-producir incesantemente y bajo el menor costo posible. Al mismo tiempo, esta mercancía, como dice Marx, es 'especial' y 'única'. No es como cualquier otra dado que tiene la capacidad de generar valor. Esta hoy en día se ha feminizado, precarizado, flexibilizado, endeudado y financiarizado. A su vez, reviste tanto una composición salarial como gratuita respecto a su valor.

Por tanto, estos feminismos acuerdan que, para sostener hoy la pregunta revolucionaria, el movimiento que pone en jaque al estado de cosas existente, es preciso ampliar la noción de 'trabajo', desbordando la categoría de salario y de sujeto asalariado. De este modo, nos proponen comprender una dinámica de la lucha de clases que incluya a las luchas trabajadoras más allá del salario y amplíen los debates sobre las condiciones laborales, porque la clase está ya sexo-genérica y racialmente determinada. Esto nos permite recuperar un presente dinámico de la noción de clase proletaria, además de una historia que comprende a lx trabajadorx asalariadx como explotadx, pero hace evidente el privilegio del salario y su colonialidad frente a un sector de la clase racializado y feminizado.

En las colonias y en los hogares, el salario es lo que cabe históricamente al blanco, al masculinizado, al heterosexual. El trabajador como sujeto jurídico, como ciudadano vendedor de una mercancía, que, desde la óptica del derecho del capital, exhibe una igualdad allí donde no solo hay una relación de explotación, sino un diferencial de explotación y dominación interclase. El resto de la clase, la mayoría, es tomada como 
un recurso — cuasi natural- que puede ser explotado y dominado hasta morir — como los femicidios en Ciudad Juárez, por ejemplo—, al mismo tiempo que funcionan como disciplinamiento de la mano de obra asalariada para bajar sus costos y recortar derechos.

Una vez considerada esta perspectiva podemos afirmar que la informalidad, la precarización y la flexibilización laboral que las feministas denunciaban sobre el trabajo doméstico y reproductivo, feminizado y racializado, no solo se reprodujo exponencialmente durante la era global neoliberal, sino que además encontró nuevos canales de transmisión y espacialidades de producción. Este proceso deviene central en las lógicas actuales de producción de valor. Cada vez se vuelve más borrosa la línea que separa las actividades generadoras de valor de aquellas que no lo generan. Se vuelven así obsoletos los parámetros basados en diferentes tipos de tareas y los modos de remuneración. Sin embargo, esto no sigue al argumento sostenido por cierto marxismo de que en el desarrollo del capitalismo las distinciones de género y raza desaparecerían por el desarrollo de las fuerzas productivas. Por el contrario, estas dinámicas complejas de valorización del capital suponen sostener las distinciones de sexo-género, raza, edad, nacionalidad hacia dentro de la clase trabajadora, y se afirman sobre diferentes procesos reproductivos y laborales.

En concreto, el capitalismo separa los procesos de producción y reproducción, al tiempo que produce diferencialmente la reproducción de la clase trabajadora. Por lo tanto, es preciso escuchar a los feminismos que amplían la noción de 'trabajo' y de 'lucha de clases' al incluir a las luchas más allá del salario y las condiciones laborales clásicas. Esto produce la valorización social de la diferencia que produce la acumulación de capital.

\section{CONCLUSIONES}

Como afirmamos en la introducción, el pensamiento de las nuevas derechas, y ciertos feminismos - populares, marxistas, materialistas y queer-, pueden ser considerados como las dos caras de la misma moneda. Son dos polos antagónicos en una relación donde uno puja por volver a un pasado cuando la jerarquía entre los géneros, los sexos, las razas y las nacionalidades era incuestionable; el otro busca revolucionar el estado de cosas actual, extrayendo su potencia y su poesía del porvenir.

Tanto las derechas antifeministas como los feminismos anticapitalistas entienden que el problema de la reproducción biosocial y, por ende, el 
control sobre los cuerpos y la sexualidad de las mujeres y feminizadas es central para la producción y valorización del capital, para la explotación y dominación de las subjetividades trabajadoras y para el mantenimiento de un orden patriarcal en el cual la norma heterosexual y la dominación masculina sigan vigentes. Instituciones económico-políticas como la familia tradicional, la propiedad privada, el trabajo asalariado, el régimen heterosexual, las jerarquías sociales y espaciales, etc. son fundamentales para garantizar la reproducción del capitalismo patriarco-colonial. De este modo, existe una disputa entre estas derechas antifeministas contra lo que llaman 'ideología de género', como parte del marxismo cultural y las luchas feministas. Esta disputa se presenta fundamentalmente a través de temas centrales para la reproducción biosocial, respecto de la organización económica deseable y el papel del Estado y del Derecho en temas como el aborto - denunciado como 'matar bebés' —, la educación sexual integral — transformada en 'ideología de género' y 'homosexualismo cultural' —, la salud reproductiva —y las prácticas sexuales 'contranatura' —, la violencia machista — cuya existencia el antifeminismo niega-, las formas de goce y uso de los cuerpos y de la anticoncepción, la identidad de género —que, según las derechas, va contra 'la naturaleza' —, el matrimonio igualitario - cuando el matrimonio solo podría llamarse tal entre un varón y una mujer-, etc.

Como vimos, para estas derechas es fundamental construir tanto teórica como políticamente un antagonismo que permita unificar a ciertos sectores sociales a partir de una identidad blanca, heterosexual, generizada - determinada sexualmente como varones y mujeres-en la medida en que poner en jaque estas estructuras y tecnologías de subjetivación haría tambalear no solo las jerarquías sociales preexistentes, sino también la productividad y valorización del capital. Estas derechas movilizan así el odio, el racismo, la xenofobia y el machismo mediante el rechazo hacia todxs aquellxs extrañxs a la norma patriarcal, colonial y capitalista. Todxs aquellxs que se organizan, rechazan y disputan la norma son considerados no solo como anormales, a los que se debe reeducar o excluir, sino como comunistas —o, en su defecto, idiotas útiles-. Son sujetxs poseídxs por un mal que la sociedad debe exorcizar y eliminar si no quiere ver socavados sus cimientos.

Respecto a esta caracterización, cabe señalar que, para ciertos pensadores o militantes de izquierda, nos encontramos frente a un anticomunismo de derechas sin una alternativa comunista en las prácticas de resistencia - luego de la crisis de las internacionales comunistas y del 
derrumbe de la uRss - Sin embargo, si el comunismo es, como afirman Marx y Engels (1970), el movimiento real que anula y supera el estado actual de cosas, los feminismos, como intentamos demostrar, y como temen sus más conspicuos detractores, cuestionan no solo un aspecto parcial de nuestras formas socioculturales, sino la institución misma de la cultura tal como la conocemos; no solo un aspecto parcial de la explotación económica sino su propia condición de posibilidad: la desposesión del trabajo reproductivo. Como movimientos teórico-políticos, los feminismos imprimen una apertura en la continuidad destructiva del capitalismo patriarco-colonial, y, en este sentido, pueden ser considerados 'comunistas'.

Desde luego, estos feminismos no son comunistas porque intenten replicar las formas organizativas de las históricas internacionales comunistas ni de los estados socialistas, sino porque organizan los modos de resistencia internacionales, regionales y locales a la dominación y la explotación colonial-patriarcal-capitalista, a través de un análisis de la reproducción social del capital. Esto se hace mediante una mutación en la relación capital-trabajo, trastocando, al mismo tiempo, los límites del sujeto de la revolución —blanco, masculino, y heterosexual-. Por eso se ha dicho, para horror de sus adversarios, que la revolución será feminista o no será.

\section{REFERENCIAS}

Alabao, N. (2019). ¿Por qué el neofascismo es antifeminista? En A. Guamán, A. Aragoneses \& S. Mar (Eds.), Neofascismo. La bestia neoliberal (pp. 12-204). Siglo XXI.

Aragoneses, A. (2019). La construcción del enemigo como base del (neo)fascismo.

En A. Guamán, A. Aragoneses, \& S. Mar (Eds.), Neofascismo. La bestia neoliberal (pp. 111-126). Siglo Xxi.

Arruzza, C. (2010). Las sin parte. Matrimonios y divorcios entre feminismo y marxismo.

Izquierda Anticapitalistteora.

Beauvoir, S. (2019). El segundo sexo. Cátedra.

Bidaseca, K. (2015). Escritos en los cuerpos racializados. Lenguas, memoria y genealogías (pos)coloniales del femininicido. Universitat de les Illes Balears.

Brown, W. (2019). In the ruins of neoliberalism. The rise of antidemocratic politics in the West. Columbia University Press. https://doi.org/10.7312/brow19384

Butler, J. (2007). El género en disputa. Paidós. 
Cooper, M. (2017). Family values. Between neoliberalism and the new social conservatism. Zone Books. https://doi.org/10.2307/j.ctt1qft0n6

Davies, W. (2016). El nuevo neoliberalismo. New Left Review, 101, 121-137.

Delphy, C. (1985) Por un feminismo materialista. El enemigo principal y otros textos. En Cuadernos inacabados 2.3 La Sal edicions de les dones.

Díaz, N. Q. (2009). Economías feminista, social y solidaria: respuestas heterodoxas a la crisis de reproducción en América Latina. Íconos: revista de Ciencias Sociales, (33), 77-89.

Dvoskin, N. (2019). El anarcoliberalismo como terraplanismo económico. Cuadernos de Economía Crítica, 5(10), 159-168.

Elman, J. (2018). La derecha sub-30. ¿Quién le teme a Agustín Laje? Revista Anfibia. http://revistaanfibia.com/cronica/quien-le-teme-a-agustin-laje-2/

Estado Mayor del Ejército Argentino. (1976). Marxismo y Subversión. Ámbito laboral.

Estado Mayor del Ejército Argentino. (1977). Marxismo y Subversión. Ámbito educacional.

Expósito, J. E. (2020). Lecturas feministas de la reproducción social. Un debate situado en tiempos de neoliberalismo pandémico. Anacronismo e irrupción, 10(19), 72-107.

Falquet, J. (2017). Pax Neoliberalia. Madreselva.

Federici, S. (2013). Revolución en punto cero. Traficantes de sueños.

Federici, S. (2015). Calibán y la bruja. Mujeres cuerpos y acumulación originaria. Tinta Limón.

Federici, S. (2018). El patriarcado del salario. Tinta Limón.

Forti, S. (2020). Los rojipardos: ¿mito o realidad? Nueva Sociedad, (288), 15-26.

Fraser, N. \& Butler, J. (2016) ¿Redistribución o reconocimiento? Un debate entre marxismo y feminismo. Traficantes de sueños.

Fraser, N. \& Sunkara, B. (2019). The old is dying and the new cannot be born: From progressive neoliberalism to Trump and beyond. Verso.

Fraser, N. (2008). Escalas de la justicia. Herder.

Fraser, N. (2014). Tras la morada oculta de Marx: Por una concepción ampliada del capitalismo. New Left Review, 86, 57-76.

Fraser, N. (2016). Las contradicciones del capital y los cuidados. New Left Review, 100, 111-132.

Haraway, D. (1995). Conocimientos situados. En Ciencia, cyborgs y mujeres (pp 313345). Cátedra.

Harcourt, B. (2018) The counterrevolution: How our government went to war against its own citizens. Basic Books.

Laclau, E. (2006). La razón populista. Fondo de Cultura Económica.

Laje, A. \& Márquez, N. (2016). El libro negro de la nueva izquierda. Ideología de género o subversión cultural. Grupo Unión.

Lazzarato, M. (2020). El capital odia a todo el mundo. Eterna Cadencia.

Lorde, A. (2002) La hermana, la extranjera. Traficantes de sueños.

Lorey, I. (2016) Estado de inseguridad. Traficantes de sueños. 
Lugones, M. (2008). Colonialidad y género. Tabula Rasa, 9, 73-101. https://doi. org/10.25058/20112742.340.

Luxemburg, R. (1968). The accumulation of capital. Modern Reader Paperbacks. Marx, K. (2002) El Capital (Tomo I, II y III). Siglo XxI.

Marx, K. \& Engels, F. (1970). La ideología alemana. Grijalbo.

Mezzadra, S. (2012). ¿Cuántas historias del trabajo? Hacia una teoría del capitalismo poscolonial. Postcolonial Studies, (14), 151-170. https://doi.org/10. 1080/13688790.2011.563458

Mezzadri, A. (2019). On the value of social reproduction: Informal labour, the majority world and the need for inclusive theories and politics. Radical Philosophy, 2(4), 33-41.

Mies, M. (2018). Patriarcado y acumulación a escala mundial. Traficante de sueños. Mudde, C. (2021) La ultraderecha hoy. Paidós.

Pérez Orozco, A. (2014). Subversión feminista de la economía. Traficantes de sueños. Preciado, P. B. (2008) Testo Yonqui. Espasa.

Ramas San Miguel, C. (2019) Social-identitarios y neoliberales autoritarios: dos corrientes en la nueva internacional reaccionaria. E n A. Guamán, A. Aragoneses, \& S. Mar (Eds.), Neofascismo. La bestia neoliberal (pp. 68-81). Siglo XXI.

Rodríguez Enríquez, C. (2015) Economía feminista y economía del cuidado. Revista Nueva Sociedad, (256).

Rolnik, S. \& Guattari, F. (2015). Micropolítica. Cartografías del deseo. Traficantes de sueños.

Said, E. (2009). Orientalismo. Debolsillo.

Saidel, M. (2019). ¿Se puede hablar de un momento fascista del neoliberalismo? Crisis de la democracia liberal y guerra contra las poblaciones precarizadas como síntomas de época, Revista Argentina de Ciencia Política, (24), 70-100

Sartre, J-P. (1948). Reflexiones sobre la cuestión judia. Sur.

Sauvêtre, P. (2019). National-néolibéralisme : de quoi le populisme est le nom. http:// sens-public.org/articles/1470/

Sazbón, J. (2002). Historia y representación. Universidad Nacional de Quilmes.

Schmitt, C . (1984). El concepto de lo político. Folios.

Segato, R. (2016) La guerra contra las mujeres. Traficantes de sueños.

Stefanoni, P. (2021). ¿La rebeldía se volvió de derecha? Cómo el antiprogresismo y la anticorrección política están construyendo un nuevo sentido común (y por qué la izquierda debería tomarlos en serio). Siglo XxI.

Svampa, M. (2015). Feminismos del Sur y ecofeminismo. Revista Nueva Sociedad, 240-256.

Traverso, E. (2016). Espectros del fascismo. Pensar las derechas radicales en el siglo XXI. Herramienta, (62). https://www.herramienta.com.ar/articulo. php?id=2555.

Valencia, S., \& Sepúlveda, K. (2016). Del fascinante fascismo a la fascinante violencia: psico/bio/necro/política y mercado gore. Mitologías hoy, 14, 75-91. https://doi.org/10.5565/rev/mitologias.395 
Zacharenko, E. (2019). Combustible neoliberal para el movimiento antifeminista. Nueva Sociedad. https://nuso.org/articulo/combustible-neoliberal-para-elmovimiento-antifeminista/imprimir/ 